\title{
EARTHQUAKE-SOIL STRUCTURE INTERACTION, SPRING AND DASHPOT MODELS, AND REAL SOIL BEHAVIOUR
}

\author{
M.J. Pender*
}

This paper was presented at the Third South Pacific Regional

Conference on Earthquake Engineering, Wellington, May 1983.

\begin{abstract}
SYNOPSIS:
The earthquake response of a simple soil-structure interaction system is discussed. The nonlinear hysteretic properties of the soil, on which the structure is founded, are modelled. It is found that the nonlinear soil behaviour leads to a reduction in the response of the structure.
\end{abstract}

\section{INTRODUCTION :}

The beginnings of this paper go back to a 1954 publication by Merritt and Housner(1) entitled: "Effect of foundation compliance on earthquake stresses in multistorey buildings". They investigated the response of multistorey buildings to earthquake acceleration records using an analogue computer. The buildings were modelled as linearly elastic with viscous damping, whilst the foundation material was linearly elastic. In the introduction to their paper Merritt and Housner make the following statement:

"... the rotation of a building on its foundation may have a very considerable effect on lengthening the natural periods of vibration of the building, with a resulting decrease on the dynamic shears and moments throughout the structure. It is clear that as the foundation material becomes increasingly soft there will be a mitigating effect upon the stresses produced in the building."

The results of their calculations verified these comments although, for the earthquake records used, it was noted that at certain values of the foundation compliance there was actually a slight increase in the actions induced in the building by the earthquake excitation.

However the magnitude of the compliance effects was not great for likely foundation compliance values. Just prior to the conclusions of the paper they stated:

"It appears that only very exceptionally would foundation yielding have a beneficial effect on earthquake stresses. To achieve this would require an exceptionally narrow building with a floating foundation on a very soft soil."

(Since the behaviour of the foundation was modelled as linearly elastic, Merritt and Housner use the word 'yielding' as synonym for 'compliance'.)

* Civil Engineering Department, University of Auckland
At the time of writing this paper the above comments can be refined by remarking that the response of a building to earthquake excitation is a function of the natural period of the structure in relation to the period (or periods) of the peak energy input in the earthquake motion. The softening effect of the foundation compliance lengthens the natural period of the soil-structure system. If this lengthening moves the period of the building system towards a period at which the input in the earthquake energy is larger, then the moments and shear forces induced in the building will be increased. Thus foundation compliance may increase or decrease the response of the structure. For the particular earthquakes used by Merritt and Housner the decrease in response was more notable than the increase.

Merritt and Housner's pioneering work was followed about a decade later by a series of papers by Parmelee et al $(2,3,4)$. A three degree of freedom system was analysed, one degree of freedom being associated with the structure and two with the foundation. The foundation material was elastic with viscous damping. Parmelee concluded that foundation compliance is likely to be significant only if the shear wave velocity of the foundation soil is less than $300 \mathrm{~m} / \mathrm{sec}$. This is a slight relaxation of the conclusion reached by Merritt and Housner, but the impression is nonetheless given that foundation compliance may be of no more than modest significance for the response of buildings under earthquake excitation. A saturated clay having a shear wave velocity of $300 \mathrm{~m} / \mathrm{sec}$ would have an undrained shear strength of about $100 \mathrm{kPa}$. Alternatively a dense sand under low confining pressure, or a medium to loose sand under higher confining pressure, would also have such a value of shear wave velocity. A clay having a $c_{u}$ of $100 \mathrm{kPa}$

is a relatively good foundation material. The use ofacompensated foundation means that even multistorey buildings could be founded on soil with $c_{u}$ a good deal less than $100 \mathrm{kPa}$. Parmelee's criterion for significant elastic soil structure interaction thus looks as if it could apply to a reasonable range of feasible foundation conditions. In the case of dense sands similar comments apply, but for loose sands the possibility of liquefaction under cyclic loading requires either densification

BULLETIN OF THE NEW ZEALAND NATIONAL SOCIETY FOR EARTHOUAKE ENGINEERING, VOL. 16, NO. 4, DECEMBER 1983 
or the use of a piled foundation.

Since Parmelee 's work in the middle to late sixties the topic of soil-structure interaction has continued to generate a steadily increasing literature, although the contributions are generally still limited to elastic-viscously damped soil. The purpose of this paper is to consider in a simple way the effect of real soil behaviour rather than the linearviscous idealisation. An assessment is made of the likely significance of the nonlinear hysteretic behaviour of soil under earthquake loading by calculating the response of a simple structure to earthquake excitation. The structure consists of a tower with a lumped mass at the top. The foundation consists of two pad footings separated by a rigid foundation beam. The structure is shown in Fig. 4. The response of the soil beneath the footings is nonlinear, thus attempting to represent the real behaviour of the foundation material.

\section{REAL SOIL BEHAVIOUR}

A frequent idealisation used in earthquake engineering for the cyclic loading of soil, along with other engineering materials, is the linear elastic-viscously damped material. Viscous damping requires that the energy dissipation per cycle increases as the frequency of the loading increases. However, it has been demonstrated many times, for example Taylor $(5)$, that for soil the energy dissipated per cycle is independent of the frequency of loading (at least over the range of frequencies of interest in earthquake engineering). Thus it is more appropriate to assume that the damping mechanism is hysteretic rather than viscous. Furthermore it is found that the amount of dissipation increases with the cyclic strain amplitude.

It is also found that the stiffness of soil is a function of strain amplitude. At strains less than approximately $10^{-4} \%$ the behaviour is linear and the strains recoverable. The shear modulus defined by this small strain behaviour is related to the shear wave velocity. As the strain amplitude increases there is a progressive decrease in the stiffness of the soil.

It is possible to represent the stiffness and damping behaviour of soil with an apparent shear modulus and an equivalent viscous damping ratio, these terms are defined in Fig. 1. In Figs. 2 and 3 data on the variation of these parameters with strain amplitude are presented for a wide range of soils. In Fig. 2 the limiting value of the shear modulus at low strains is apparent. Fig. 3 the equivalent viscous damping values are plotted, at very small strains the damping approaches zero but at large strains the damping values are quite large. The information in these diagrams shows that at very small strains soil behaves essentially as an elastic material but as the strain amplitude increases there is increasing nonlinearity and also an increase in the hysteretic damping. The important point is that these two properties, stiffness and damping, are not independent as a change in one produces a change in the other.

In Figs. 2 and 3 a solid line is plotted passing through the scattered data points. This has been generated by a mathematical model for soil stress-strain behaviour. The model is based on the idealisation that soil is a work hardening plastic material. The most attractive feature of the model is the small number of parameters needed to describe a given soil, and the fact that these can be obtained from routine tests. The curves in Figs. 2 and 3 are not an attempt to position a best fit curve through the data, rather they are intended to illustrate that the soil model can represent the strain dependent modulus and damping properties of soils. The lines may be recalculated for various initial conditions, such as overconsolidation and values of $\mathrm{K}$. The details of the model are discussed by Pender $(6,7,8)$. The data in Figs. 2 and 3 refer to soils which do not undergo liquefaction. Similarly the soil model does not describe liquefaction.

This soil model is the basis for the calculation of the nonlinear soil behaviour beneath a loaded footing discussed below.

\section{CYCLIC LOADING OF A FOOTING RESTING ON AN ELASTIC HALF SPACE}

The dynamic behaviour of a footing resting on an elastic soil layer is often represented by an equivalent spring mass system with viscous damping. The major requirements in this modelling process are the values to be assigned to the spring stiffness, damping coefficients and magnitude of the mass. To this end considerable insight has been provided by the mathematical solution to the dynamic behaviour of a footing resting on an elastic half space. The details are discussed by Richart, Hall and Woods(9) and by Newmark and Rosenbleuth (10). The solution shows that it is possible to use a spring mass system to model the behaviour of a footing. However it is found that the stiffness coefficients are frequency dependent, but fortunately, for the range of frequencies of interest in earthquake engireering, the frequency dependence is slight. Thus it is common practice to use a spring and dashpot system having frequency independent stiffness and damping coefficients for modelling earthquake behaviour. This is illustrated in Fig. 5.

For the vertical vibration of a rigid circular footing resting on the surface of an elastic half space the spring stiffness coefficient is given by:

$\mathrm{K}=\frac{4 \mathrm{G} a}{\mathrm{l}-\mathrm{v}}$

where $K$ is the spring stiffness

$G$ is the shear modulus of the soil

$v$ is Poisson's ratio for the soil

a is the radius of the footing

This stiffness is the same as the static stiffness of the footing. 


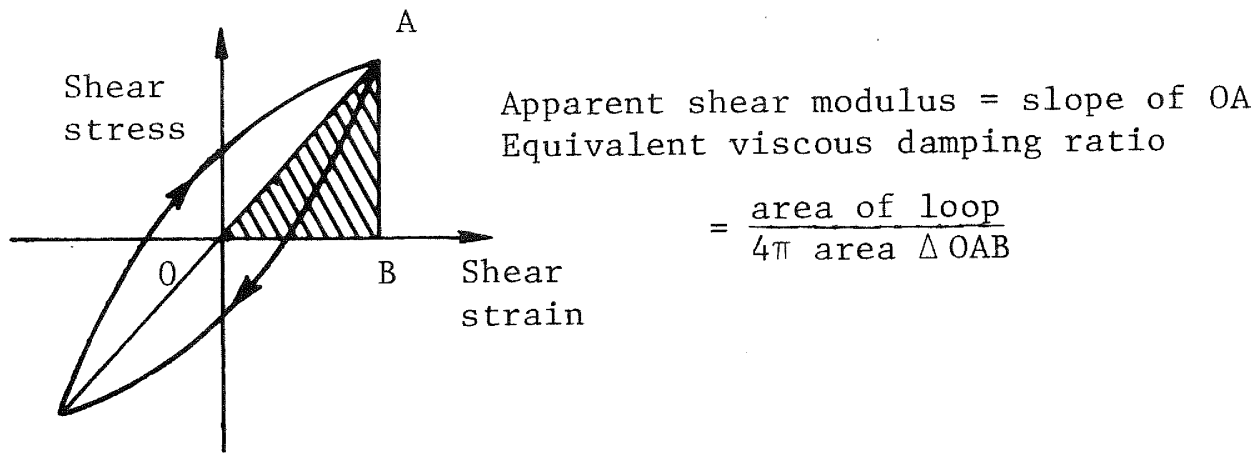

Fig. 1 : Definition of Apparent Shear Modulus and Equivalent Viscous Damping Ratio

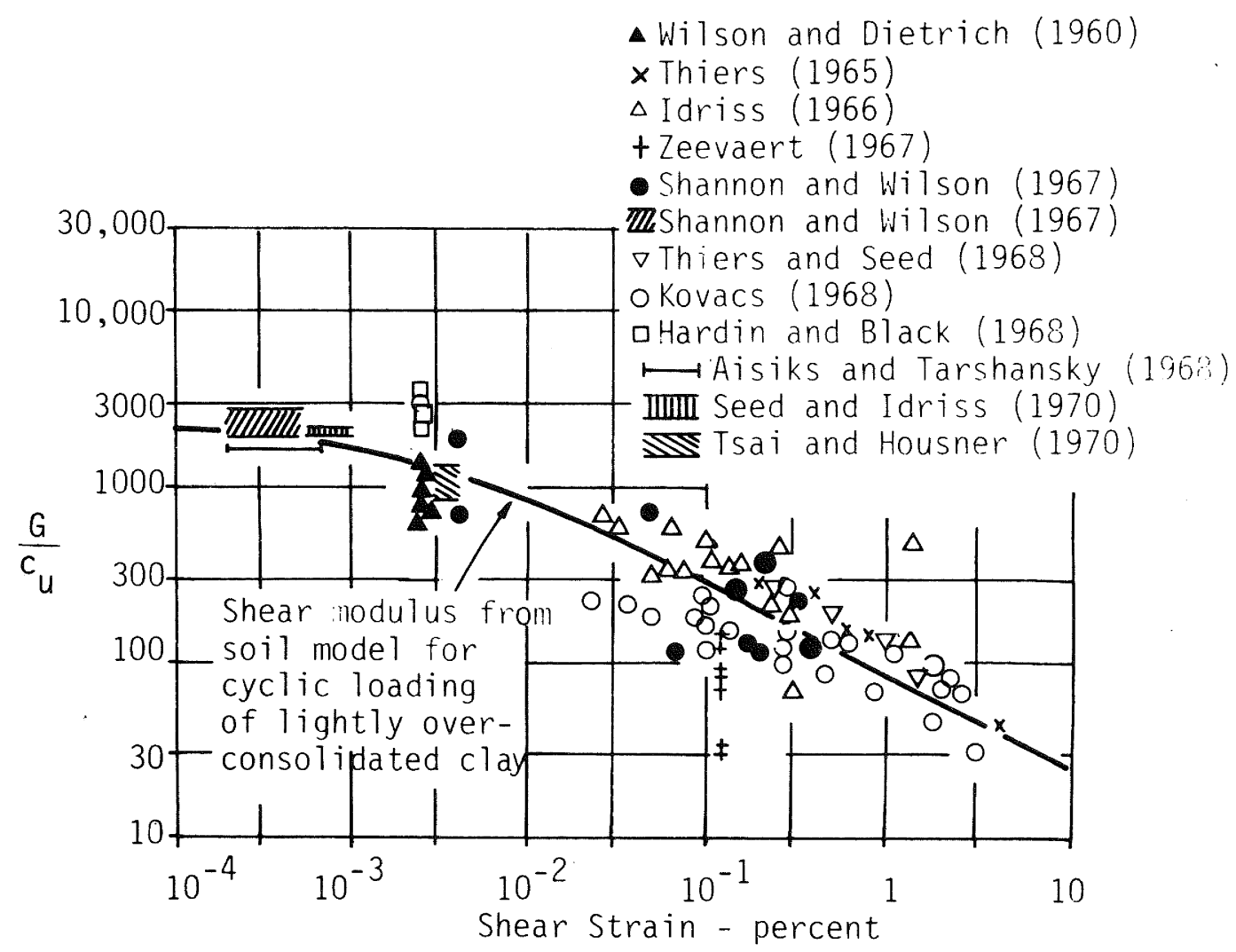

Fig. 2 : Shear Moduli for Saturated Clays 


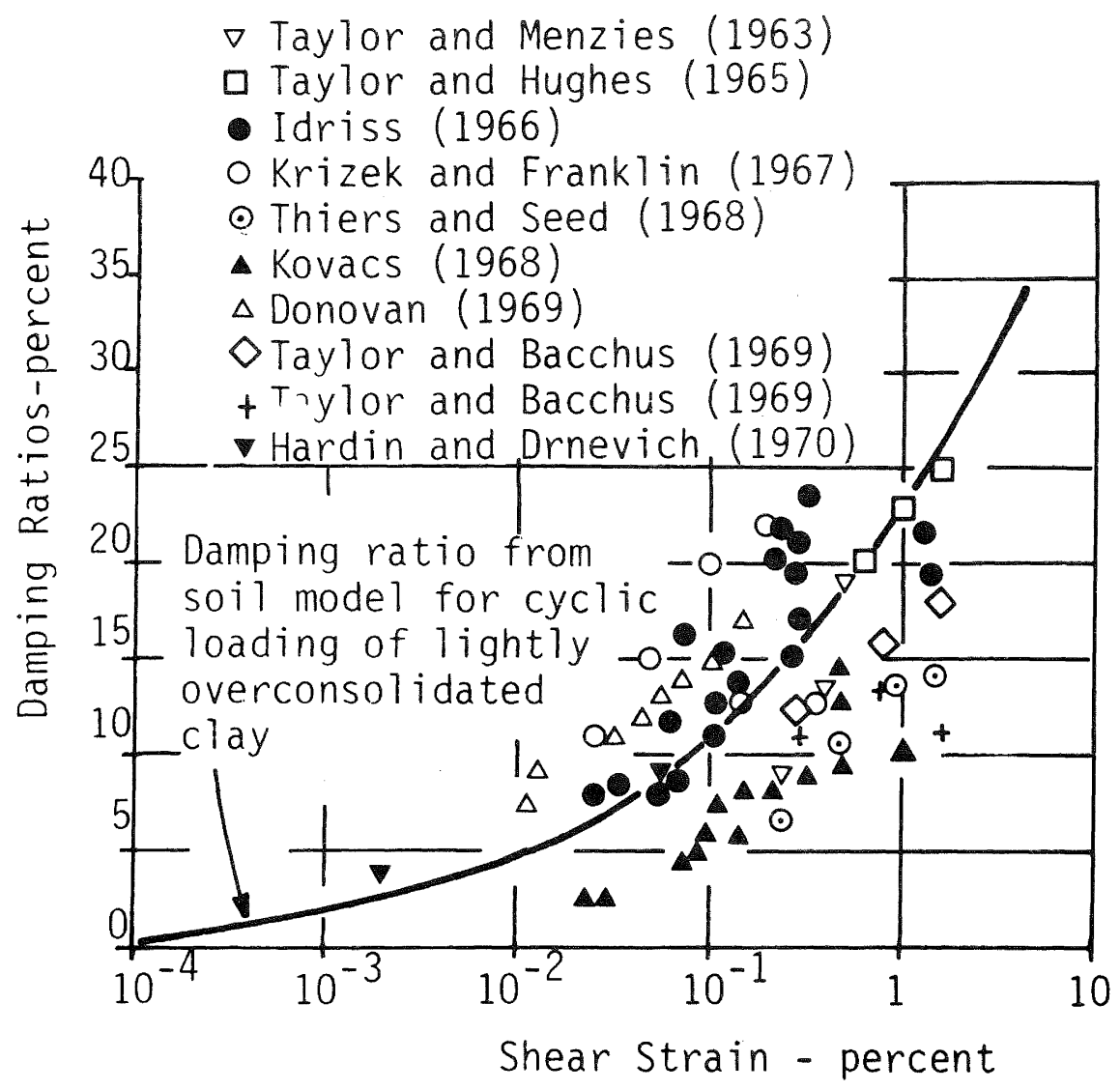

Fig. 3 : Damping Ratios for Saturated Clays

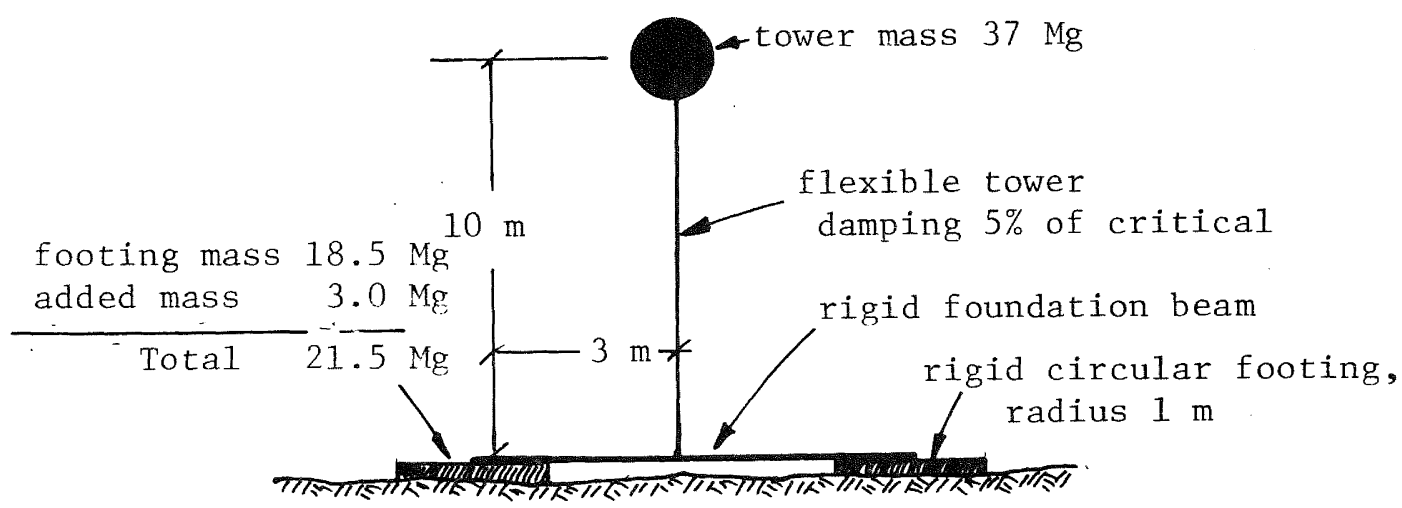

Fig. 4 : Soil-Structure Interaction Model Analysed 
Rosenbleuth and Newmark (10) give the following expression for the viscous damping coefficient that models the loss in energy from the footing by radiation:

$\mathrm{C}=1.79 \sqrt{\mathrm{K} \mathrm{pa}}^{3}$

where $\rho$ is the density of the soil.

The magnitude of this damping coefficient for vertical vibration is quite large, expressed in terms of the ratio of the value required for critical damping it is about $30-40 \%$.

A further feature of the modelling of a footing resting on a half space is the mass of the soil that vibrates in harmony with the footing - the so-called added mass. Richart and whitman(11) have shown that for higher frequencies of excitation, such as might be associated with a machine foundation, the added mass is negligible. For the earthquake range of frequencies Newmark and Rosenbleuth (10) suggest that the following added mass be used:

$$
\mathrm{M}_{\text {added }}=1.50 \mathrm{pa}^{3}
$$

Equations (1), (2) and (3) provide a means for converting an analytically complex problem that of the vibration of a rigid footing resting on an elastic half space, to the much simpler problem of the response of an equivalent springmass-dashpot system.

\section{STRUCTURE-FOUNDATION MODEL}

The response of the idealised structure shown in Fig. 5 was calculated to an earthquake acceleration record. The intention was to keep the details of the structural model as simple as possible, whilst maintaining the suggestion of something that might be real. A flexible, elastic-viscously damped, tower with a lumped mass at the top is connected to a rigid foundation beam which is supported on two rigid circular footings. The spacing between the footings is such that there is no interaction between them. The total mass of the structure is distributed half and half between the tower mass and the foundation masses.

The modelling of the behaviour of the soil beneath each of the footings is the main innovation introduced in this paper. The zore of soil immediately beneath the footing will deform nonlinearly. The soil further away will deform elastically. This idea is illustrated in Fig. 6. Stress path computations show that the zone of soil involved in nonlinear strains is about one footing diameter deep $\mathrm{cf}$. the Appendix. The nonlinear spring in Fig. 6b incorporates the stiffness and the hysteretic damping illustrated in Figs. 2 and 3. In this paper no added mass is associated with the nonlinear springs. The linear viscously damped spring represents the small strain elastic behaviour of the soil remote from the footing, the radiation damping is simulated by the viscous damping element.

At this point some clarification of the damping phenomenon is required.

In section 2 the hysteretic damping

discussed refers to the energy dissipated in deforming a small element of soil. This energy is thus dissipated internally and the damping is referred to as material damping. On the other hand when a footing is resting on the surface of a half space energy is lost from the region of the footing through radiation to infinity. This is discussed in section 3 and referred to as radiation damping, it is modelled as a viscous phenomenon. The behaviour of a footing on a layer of soil thus has both of these damping mechanisms present. In the soil close to the footing large material damping may be present. Energy not dissipated in this mechanism is then radiated away.

The two springs in series in Fig. $6 \mathrm{~b}$ can be reduced to an equivalent viscously damped spring. The stiffness and damping of this are given by:

$k=k_{e} /\left(k_{e}+k_{n}\right)$

$c=k_{c} c_{e} /\left(k_{e}+k_{n}\right)$

where $\mathrm{k}_{e}$ and $\mathrm{c}_{e}$ are the stiffness and damping values for the spring representing the small strain behaviour of the soil

$k_{n}$ is the stiffness of the nonlinear spring which incorporates the hysteretic damping

The obvious means of calculation of $k_{n}$ is the use of a finite element method. This might be feasible for static loading but is too expensive for the calculation of response spectra. Rather a numerical version of the stress path method, has been developed which provides a simple method of evaluation of the footing stiffness. This is described in more detail in the Appendix.

Having settled the details of the modelling of the soil beneath the footings the structure in Fig. 5 can be represented as shown in Fig. 7a. There are three degrees of freedom in this model: the horizontal displacement of the tower mass and the vertical displacement of the two foundation masses. The displayed shape of the structure is shown in Fig. $7 \mathrm{~b}$. The equations of motion for the system are:

$$
\begin{aligned}
& {\left[\begin{array}{ccc}
M & \frac{M h}{2} & -\frac{M h}{2 l} \\
\frac{M h}{2 l}\left(m+\frac{M h^{2}}{4 l^{2}}\right) & -\frac{M h^{2}}{4 \ell^{2}} \\
-\frac{M h}{2 l} & -\frac{M h^{2}}{4 l^{2}} & \left(m+\frac{M h^{2}}{4 l^{2}}\right)
\end{array}\right]\left\{\begin{array}{c}
\ddot{u} \\
\ddot{u}_{l} \\
\ddot{u}_{r}
\end{array}\right\}+\left[\begin{array}{lll}
C & 0 & 0 \\
0 & C_{l} & 0 \\
0 & 0 & C_{r}
\end{array}\right]\left\{\begin{array}{c}
\dot{u}_{l} \\
\dot{u}_{\ell} \\
\dot{u}_{r}
\end{array}\right\}+} \\
& {\left[\begin{array}{ccc}
k & 0 & 0 \\
0 & k_{\ell} & 0 \\
0 & 0 & k_{r}
\end{array}\right]\left\{\begin{array}{l}
u \\
u_{\ell} \\
u_{r}
\end{array}\right\}=M \ddot{u}_{g}\left\{\begin{array}{c}
-1 \\
-\frac{h}{2 l} \\
\frac{h}{2 \ell}
\end{array}\right\}}
\end{aligned}
$$


The terms in these equations are defined in Fig. 7. The stiffness and damping terms $\mathrm{K}_{\ell}, \mathrm{K}_{r}$ and $\mathrm{C}_{\ell}, \mathrm{C}_{r}$ are nonlinear and calculated from equations (4) and (5). An incremental method of solution for such nonlinear equations is described by clough and Penzien(12). This was used to calculate the response of the system. The stiffnesses $K_{\ell} K_{r}$ and the damping values $C_{\ell}$ and $C_{r}$ are then tangent values at some point on the stress-strain loop. The value of $\mathrm{k}_{\mathrm{n}}$ in equations (4) and (5) is the required tangent stiffness for the calculation of $\mathrm{K}_{\ell}, \mathrm{K}_{r}$ and $\mathrm{C}_{\ell}$ and $\mathrm{C}_{r}$. It is readily evaluated from the stress path approach described in the Appendix. These stiffness values are evaluated at each time increment during the solution process.

\section{RESULTS}

The solution of equations (6) was obtained to the acceleration record of the Caltech $\mathrm{Cl}$ synthetic earthquake, Jennings et al (13). This is supposed to be representative of the motion in the epicentral region of a magnitude 5.5 to 6 earthquake. The record has a length of 12 seconds. The digitisation interval for the record is 0.025 secs. For the numerical solution each of these time steps was further subdivided into ten steps. The peak ground acceleration of the record is $0.068 \mathrm{~g}$, it was scaled to provide a range of peak accelerations.

The dimensions of the structure are: tower height $10 \mathrm{~m}$, length of foundation beam $6 \mathrm{~m}$, radius of footings $1 \mathrm{~m}$, tower mass $37 \mathrm{Mg}$, foundation mässes $18.5 \mathrm{Mg}$ each. With a soil dersity of $2 \mathrm{Mg} / \mathrm{m}^{3}$ the added mass for each footing given by equation (3) is $3 \mathrm{Mg}$, which is small in relation to the other masses. The tower has a damping coefficient of $5 \%$ of critical damping.

\section{(a) Elastic response}

Elastic response spectra are plotted in Fig. 8. The ordinate in these spectra is the ratio between the peak value of the absolute acceleration of the tower mass to the peak ground acceleration in the earthquake record. It thus represents the magnification of the ground acceleration by the structure. These three spectra apply to elastic behaviour as the strains from the nonlinear soil model are set to zero. The spectra are for a rigid foundation, an elastic foundation with a shear wave velocity of $300 \mathrm{~m} / \mathrm{sec}$, and thirdly for an elastic foundation with a shear wave velocity of $100 \mathrm{~m} / \mathrm{sec}$. In each of these cases there is radiation damping from the footings with a damping coefficient calculated from equation (3). As expected from Parmelee's work there is very little difference between the spectra for a rigid foundation material and that for which the shear wave velocity is $300 \mathrm{~m} / \mathrm{sec}$. In the case where the shear wave velocity is $100 \mathrm{~m} / \mathrm{s}$ there are noticeable differences for tower periods less than 0.6 secs. For some periods the response is markedly reduced and for others there is an increase. This confirms the comment made in the introduction that the effect of the foundation flexibility depends on whether the period of the structure-foundation system moves toward or away from a period at which the energy in the earthquake record has a local maximum.

\section{(b) Nonlinear response}

In this case the footings are assumed to rest on an overconsolidated clay with an undrained shear strength of $50 \mathrm{kPa}$. If from Fig. 2 the ratio between the small strain shear modulus, $G$, and $C_{p}$ is taken as 1500, the shear wave velocilty is found to be $200 \mathrm{~m} / \mathrm{sec}$. The footings are so proportioned that the static factor of safety against bearing capacity failure is 3.0. In Fig. 9 the response spectra for three different scalings of the earthquake record are compared with the spectrum for a rigid foundation. Although the relations between the individual spectra are quite complex, particularly at low tower periods, it is clear that the nonlinear hysteretic behaviour leads to a substantial reduction in the response of the structure. As the peak ground acceleration increases the amplification of the ground acceleration decreases. This can be regarded as a natural base isolation phenomenon. For example with a tower period of 0.5 secs. the shear force induced in the tower when the soil behaves nonlinearly is $56 \%$ of that for the rigid foundation case with a peak ground acceleration of $0.07 \mathrm{~g}$, and $38 \%$ of that for the rigid foundation case when the peak ground acceleration is $0.27 \mathrm{~g}$.

The maximum footing settlements for the record with a peak ground acceleration of $0.27 \mathrm{~g}$ are of the order of $12 \mathrm{~mm}$. Thus the nonlinear effects demonstrated in Fig. 9 do not require large footing settlement. For the longer tower periods there is a tendency for uplift of one of the footings to occur. These points have not been plotted in Fig. 9. If a further degree of freedom was introduced to the system and horizontal displacement of the foundation beam allowed then additional nonlinear effects would be introduced and the nonlinear spectra would be further differentiated from the elastic-rigid base spectrum. The results in Fig. 9 lead to essentially the same conclusions as the experi mental work reported by Taylor et al (14) on the cyclic behaviour of model footings on sand and clay.

\section{The spectra in Fig. 9 are} associated with a static factor of safety of 3.0 for each of the footings. It is expected that the nonlinear behaviour of a footing would increase with decreasing static factor of safety. In Fig. 10 spectra are plotted for the case with the static factor of safety of the footings of 10.0. It is clear that in this case the nonlinear strains are much smaller and hence the nonlinear spectra are very much closer to the elastic spectrum for a rigid foundation material.

\section{CONCLUSIONS}

Three conclusions are reached from 


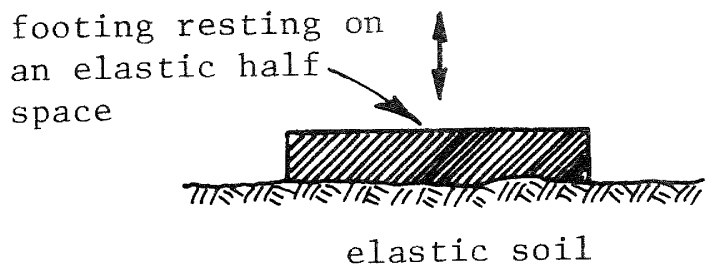

(a)

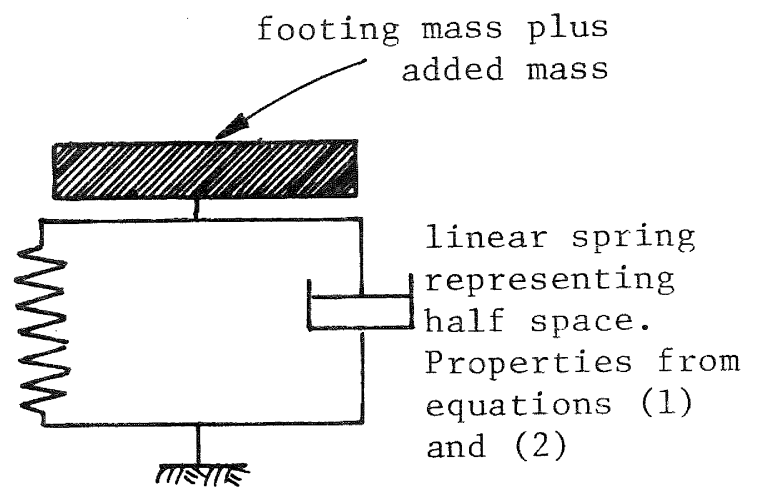

(b)

Fig. 5 : Vibration of a Footing on an Elastic Half Space (a) Physical Situation; (b) Equivalent SpringMass Representation

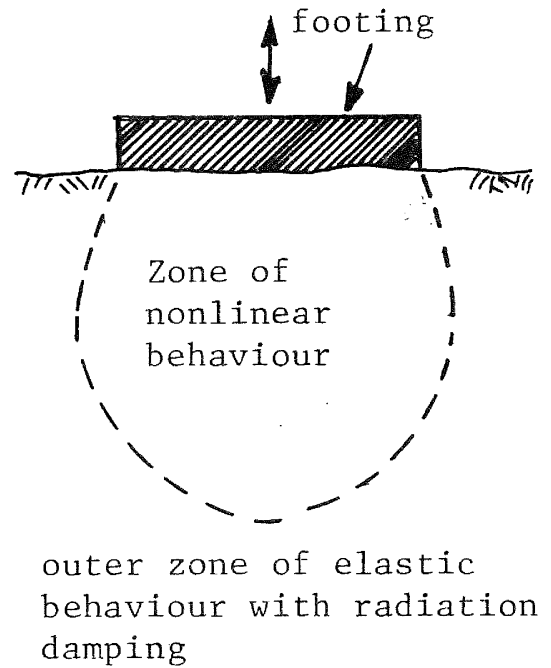

(a)

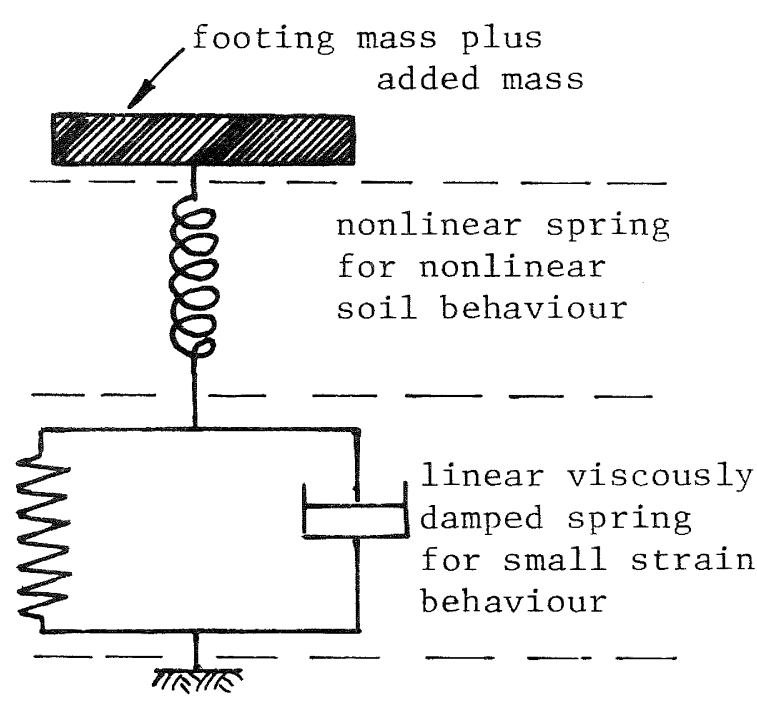

(b)

Fig. 6 : Modelling of Nonliear Soil Behaviour Beneath a Footing (a) Physical Situation; (b) Representation with and Equivalent System 

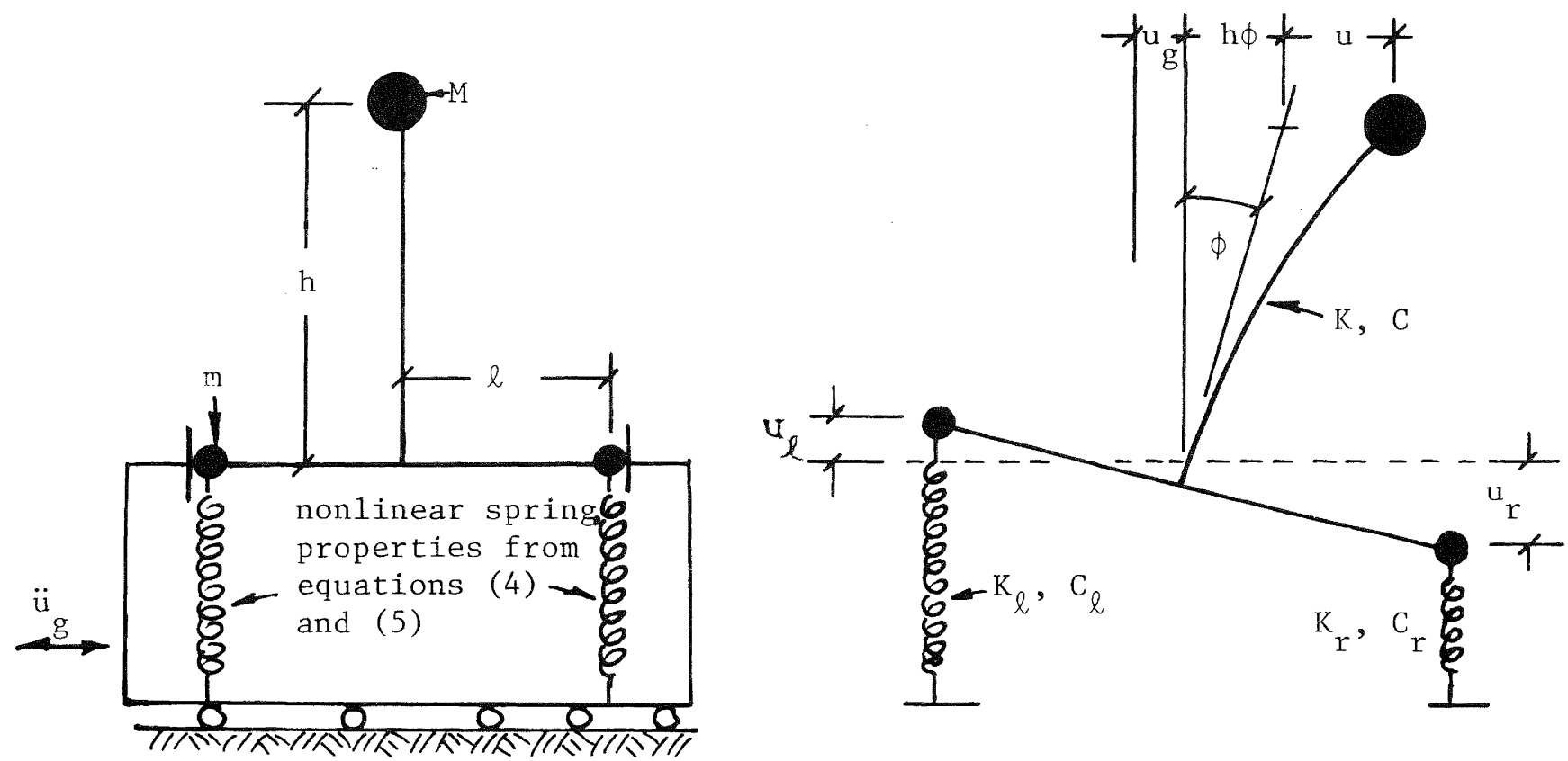

Fig. 7 : Idealisation of Soil-Structure Interaction Mode1 in Fig. 4

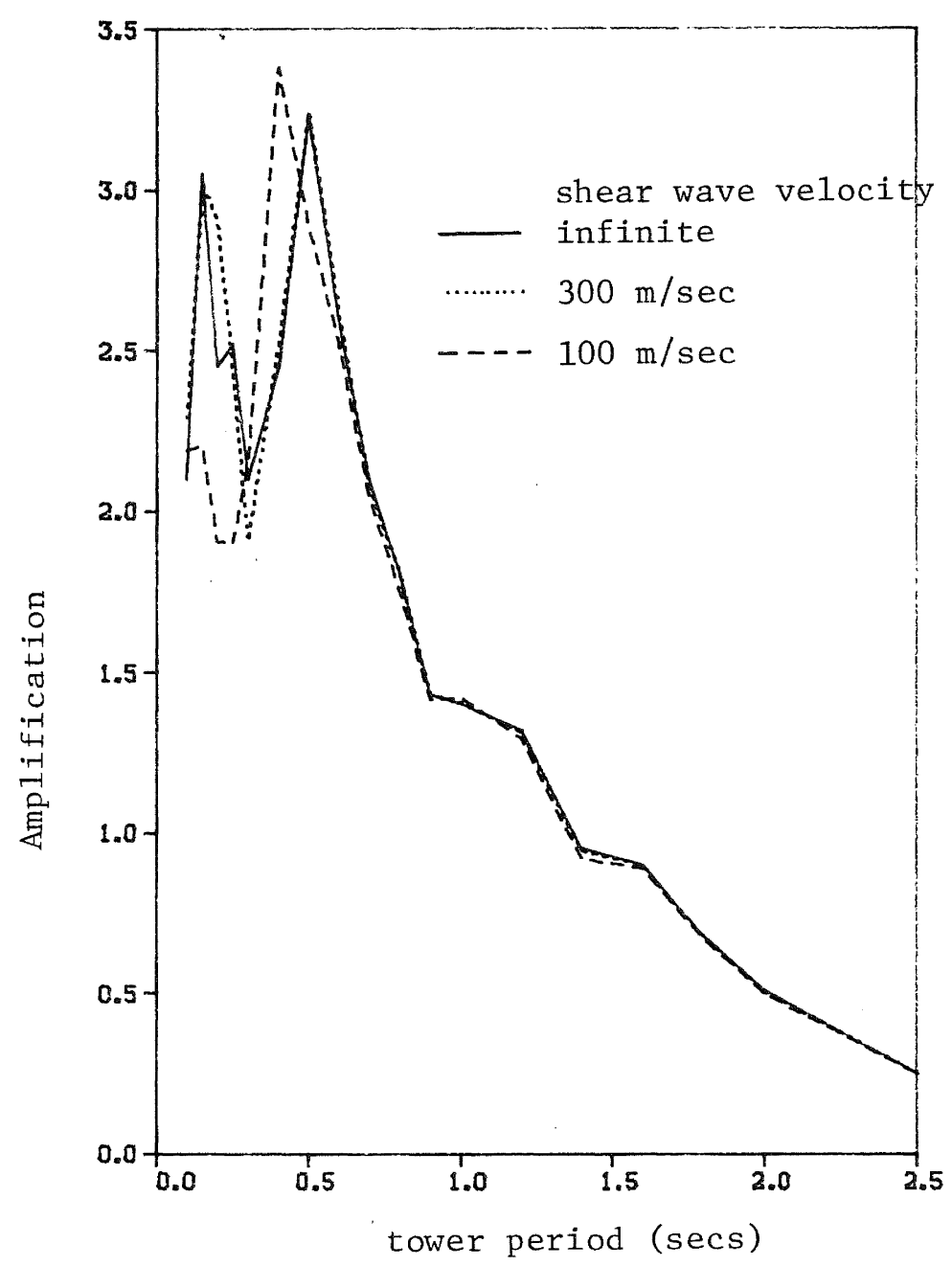

Fig. 8 : Response Spectra for Elastic Response of the SoilStructure Interaction Model 


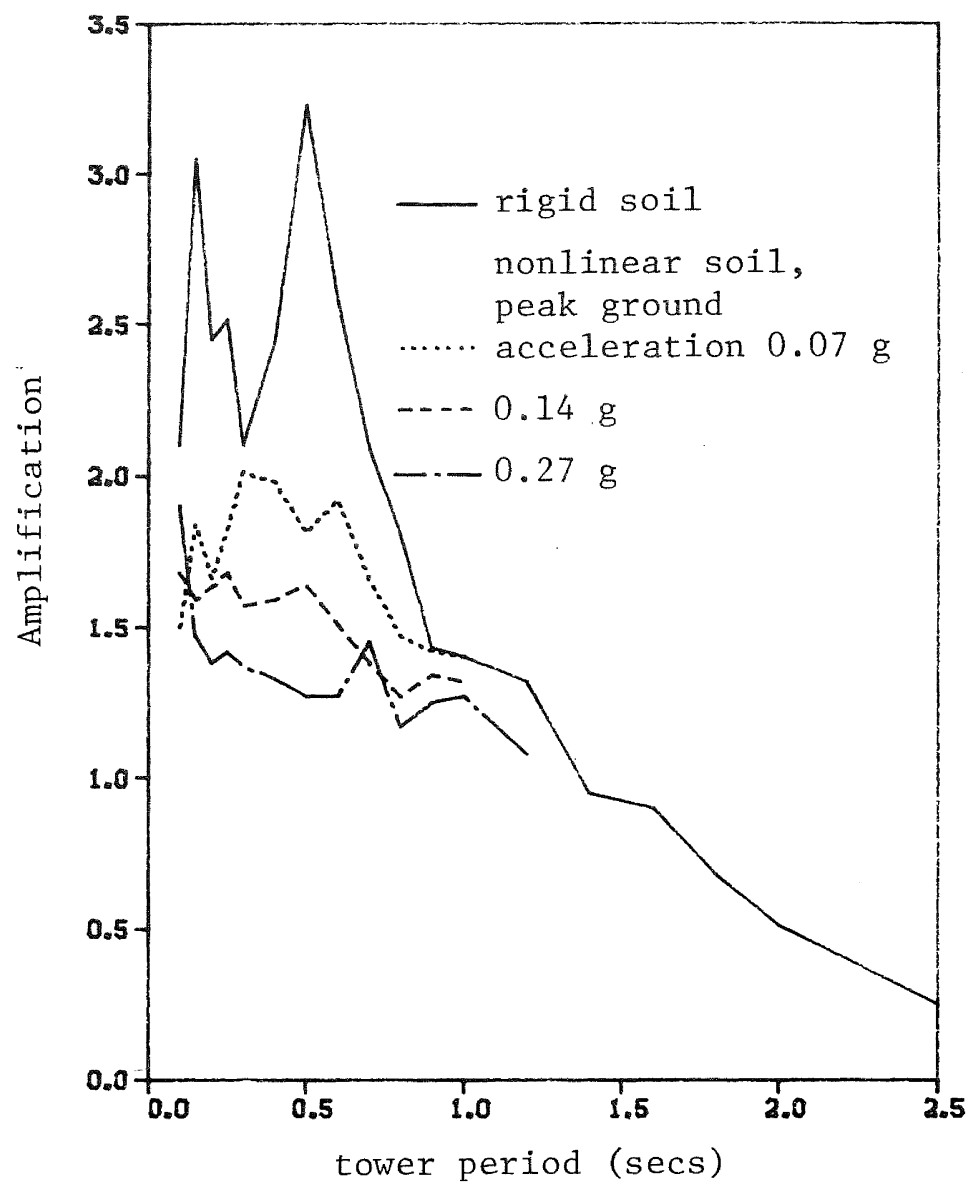

Fig. 9 : Response Spectra for the Soil-Structure Interaction Model with Nonlinear Soil Behaviour Beneath the Footings. (Static Factor of Safety for the Footings 3.0)

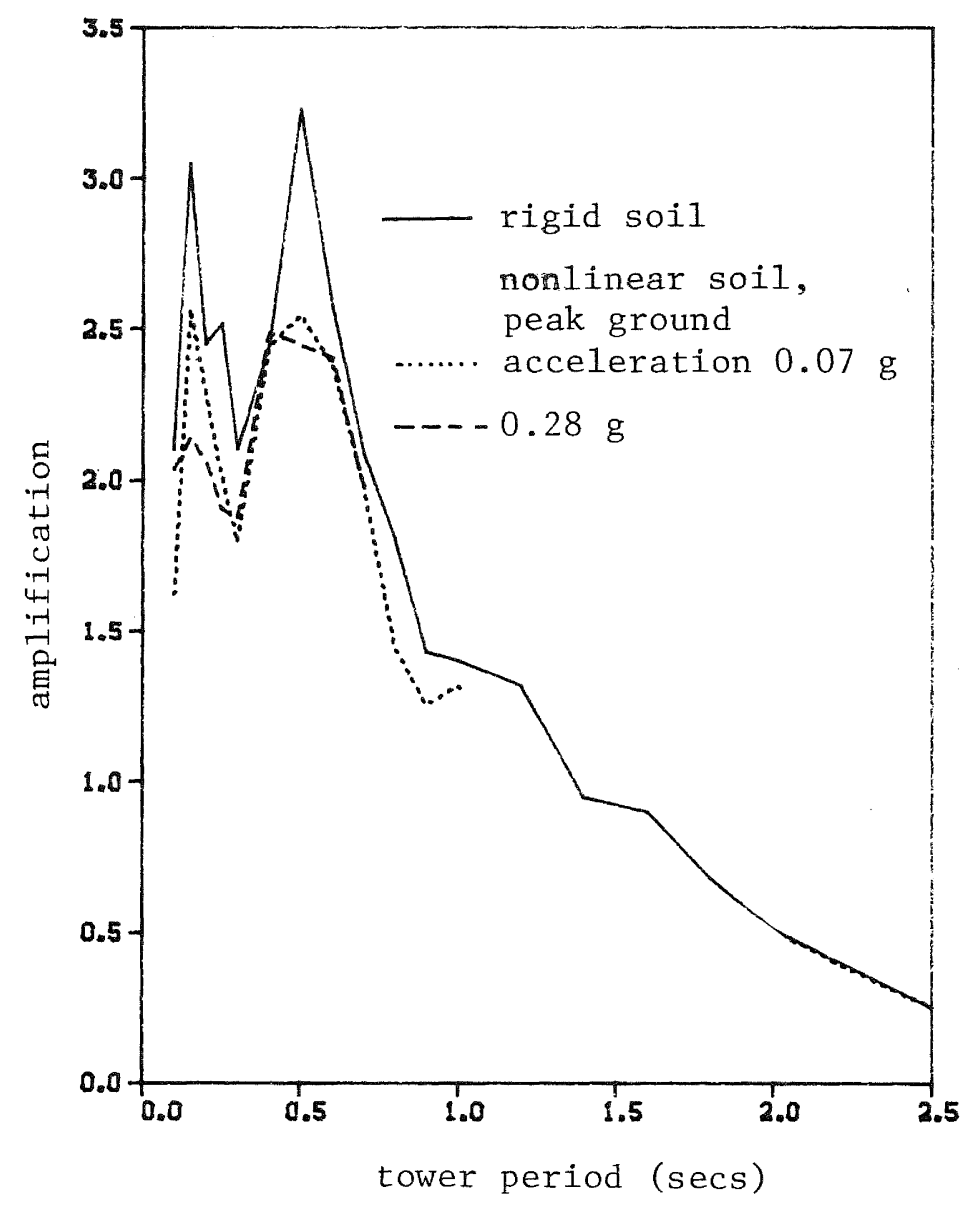

Fig. 10 : Response Spectra for the Soil-Structure Interaction Model with Nonlinear Soil Behaviour Beneath the Footings. (Static Factor of Safety for the Footings 10.0) 
the above results.

Firstly for an elastic soil the magnitude of the added mass that vibrates in harmony with the footing is small in comparison with the structural masses. This will not be true for large footings.

Secondly nonlinear behaviour of the soil beneath a footing results in a significant reduction in the response of the system. As the peak ground acceleration is increased this reduction is further enhanced, so that the moments and shear forces induced in the structure during a range of earthquakes of increasing severity do not increase in proportion to the increase in the peak ground acceleration. Furthermore the settlements of the footings resulting from nonlinear behaviour are quite modest.

Thirdly the extent of the nonlinear effects is related to the static factor of safety of the footing against bearing capacity failure. It has been shown that substantial nonlinear behaviour is evident when the factor of safety is 3 , but with a factor of safety of 10 the nonlinear effects, for the range of peak ground accelerations used, are much smaller.

\section{ACKNOWLEDGEMENTS:}

The content of this paper is a development of a presentation on the same topic to a Continuing Education Seminar in Auckland in 1978. The writer acknowledges helpful discussions with Prof. P.W. Taylor and Drs T.J. Larkin and B.J. Davidson of the Civil Engineering Department, University of Auckland.

\section{REFERENCES :}

(1) Merritt, R.G. and Housner, G.W. (1954) "Effect of Foundation Compliance on Earthquake Stresses in Multistorey Buildings", Bulletin of the Seismological Society of America, Vol. 44 No. 4 , pp 551-569.

(2) Parmelee, R.A. (1967) "BuildingFoundation Interaction Effects", Proc. ASCE, Jnl. Eng. Mech. Div., Vol. 93 EM3, pp 131-151.

(3) Parmelee, R.A., Perelman, D.S., Lee, S.L. and Keer, L.J. (1968) "Seismic Response of Structure Foundation Systems", Proc. ASCE, Jnl. Eng. Mech. Div., Vol. 94 EM6, pp 1295-1315.

(4) Parmelee, R.A. and Wronkiewicz, J.H. (1971), "Seismic Design of SoilStructure Interaction Systems", Proc. ASCE, Jnl. Struct. Div., Vol. 97 SM10, pp 2503-2517.

(5) Taylor, P.W. (1971) "The Properties of Soils under Dynamic Stress Conditions, with Applications to the Design of Foundations in Seismic Areas", Report No. 79 Civil Engineering Department, University of Auckland.

(6) Pender, M.J. (1978), "A Model for the
Behaviour of Overconsolidated Soil", Geotechnique, Vol. 28 No. 1, pp 1-25. Estimating the Pore Pressures and Displacements beneath Embankments on Soft Natural Clay Deposits", Proc. Roscoe Memorial Symposium, Cambridge, ed. R.H.G. Parry, Foulis.

Hira, A.N. (1980) "Stress Path Settlement Prediction Using a Soil Model", Report No. 233, Civil Engineering Dept., University of Auckland.

Hoeg, K., Andersland, O.B. and Rolfsen, E.N. (1969) "Undrained Behaviour of Quick Clay under Load Tests at Asrum", Geotechnique, Vol. 19 No. 1, pp 101-115.

\section{Appendix: NONLINEAR FOOTING STIFFNESS}

As explained in section 4 the nonlinear footing stiffness was evaluated with a numerical version of the stress path method.

The measured load settlement behaviour of a circular embankment on a layer of clay is reported by Hoeg et al (18). Finite element computations by Graham (15), using the soil model referred to in this paper, 
produced a reasonable description of the behaviour of the embankment. The stress path method described here was found to give results in close agreement with Graham's finite element results. The comparison is given in Fig. Al. The use of a finite element method to evaluate the nonlinear footing stiffness for the calculation of the response spectra in Figs. 9 and 10 would be extravagant, hence the need for the much simpler stress path approach.

The main concept of the numerical stress path method was developed by Burland (16). In this it is assumed that the stresses induced in the soil due to surface loading are the same as those for elastic behaviour. Using this stress field, the soil strains are calculated with an appropriate soil model. Hira(17) applied the soil model used in this paper to the method.

Graham's (15) finite element studies, and also many others, show that the vertical stress distribution in a nonlinear soil follows closely that in an elastic material under the same load conditions. However the horizontal stress change in the soil is somewhat greater in the nonlinear than in the elastic medium. This means that (the
settlements calculated by Burland and Hira(17) tend to be an overestimate, particularly as failure is approached. This problem was overcome herein by the use of a modified stress distribution in which a pseudo Poisson's ratio greater than 0.50 was used. Values of Poisson's ratio greater than 0.50 are not permissible for the solution of an elastic problem. However all that is required here is a stress distribution which satisfies equilibrium. This is not affected by the value of Poisson's ratio.

The response of the circular footings to each load increment was evaluated as follows. All the calculations were done for a characteristic point one footing radius beneath the centre of the footings. This is where the nonlinear strain increments are maximum. Using a value of 1.0 for the pseudo Poisson's ratio the stress increments are calculated. The soil model then gives the strain increment at that point. The strain increment is modified by an averaging factor to get the average strain for the soil contributing the nonlinear strains, i.e. over a depth equal to one footing diameter. (The value of the averaging factor and also the position of the characteristic point was found by some preliminary calculations in which the soil profile was divided into a number of thin layers and the stresses and strains calculated at the centre of each layer.) The calculation of the incremental nonlinear stiffness is then straightforward. Figure Al shows that this technique gives settlements which compare well with those obtained by nonlinear finite element analysis. 